\title{
A Estrada de Ferro São Paulo-Rio Grande na formação econômica regional em Santa Catarina*
}

\author{
Alcides Goularti Filho**
}

\section{Resumo}

O objetivo deste artigo é analisar e discutir a construção e a expansão da Estrada de Ferro São Paulo-Rio Grande (EFSPRG) no Brasil meridional, com ênfase nos trechos do território catarinense no meio oeste e planalto norte. O texto está dividido em três tópicos. Inicialmente será feita uma breve introdução que apresenta os motivos da expansão ferroviária no Brasil meridional. Em seguida, será analisada a construção do trecho catarinense dentro do complexo ervateiro e madeireiro, destacando o trecho entre Porto União-Rio Uruguai, no meio oeste catarinense. E por último, será discutida a integração do planalto norte por meio do ramal Porto União-São Francisco do Sul. O primeiro trecho, no meio oeste, foi construído entre 1907 e 1910, já o segundo, no planalto norte, foi mais lento, entre 1906 e 1917. Ambos os trechos faziam parte do fragmentado sistema ferroviário catarinense, que estava concentrado nas regiões exportadoras conectadas com os portos, sem uma integração intra-regional.

Palavras-chave: Ferrovias; História; Economia; Santa Catarina.

* Pesquisa financiada pelo CNPq e FAPESC

** Professor do Curso de Economia da UNESC, Doutor em Economia pela UNICAMP. Grupo de Pesquisa História Econômica e Social de Santa Catarina (alcides@unesc.net).

Geosul, Florianópolis, v. 24, n. 48, p 103-128, jul./dez. 2009 
GOULARTI FILHO, A. A Estrada de Ferro São Paulo-Rio Grande na ...

The Estrada de Ferro São Paulo-Rio Grande in regional economic formation in Santa Catarina

\begin{abstract}
This paper aims at analyzing and discussing the construction and expansion of São Paulo-Rio Grande Railroad (EFSPRG) in Santa Catarina. The text is divided into three topics. There is a brief introduction that analyzes the reasons for the railway expansion in the southern Brazil. In the sequence, the text studies the building of Santa Catarina's line in the tea plantation and wood exploration region, between Porto União and the Uruguay River. Finally, the paper discusses the integration of the northern plateau through the line Porto União-São Francisco do Sul. The first railway, in the middle west of Santa Catarina, was built between 1907 and 1910; the second railway, in the north plateau, was built between 1906 and 1917. Both railways were part of the fragmented railway system in Santa Catarina, which was concentrated in the exporting regions integrated by the ports, without an intra-regional integration.
\end{abstract}

Key word: Railroads; History; Economy; Santa Catarina.

\title{
Introdução
}

A necessidade de uma integração ferroviária entre as três províncias do Sul do Império no final do século XIX está associada a quatro fatores: econômico, militar, territorial e demográfico. Econômico: nas províncias do Paraná e Santa Catarina, destacavam-se duas mercadorias dentro do padrão de acumulação agrário mercantil exportador, a erva-mate e a madeira. Ambas eram exploradas de forma artesanal e necessitavam de estrutura de transporte para serem escoadas para os portos. Além destas duas fontes de acumulação, a venda da terra pelas companhias colonizadoras aos imigrantes era outra fonte de valorização do capital. Militar: como estratégia de defesa, a construção de uma ferrovia daria mais agilidade e segurança para o Brasil, que já havia sofrido ameaças do Paraguai (Guerra do Paraguai) e 
Argentina (Questão de Palmas). Territorial: o conflito com a Argentina em torno da Questão de Palmas, em 1895, obrigou o Brasil a demarcar melhor suas fronteiras para definir o território. Demográfico: a fundação de colônias no Brasil meridional agilizava a concessão de terras às companhias colonizadoras e gerava mão-de-obra para as novas atividades econômicas. Estes quatros fatores estavam dentro de um movimento maior que era a transformação de economias naturais em economias mercantis. A ferrovia levou o capitalismo para o Campo de Palmas.

Nesta região, com a chegada da ferrovia e com o início da colonização e das atividades econômicas extrativistas, houve uma decomposição da economia de subsistência e um extermínio da população indígena local. Em seguida, após a construção da ferrovia, vieram os investimentos estrangeiros acompanhados de empréstimos, que se desdobraram no militarismo. Para Rosa Luxemburgo (1985), este é o caminho percorrido pelo capital na busca de novos mercados como condição sine qua non para a sua valorização.

O objetivo deste artigo é descrever e analisar a inserção das ferrovias catarinenses na formação econômica do meio oeste, planalto norte e norte, formadas pelas respectivas linhas: Porto União-Rio Uruguai (meio oeste) e Porto União-São Francisco do Sul (planalto norte e norte).

\section{A ferrovia na integração do Brasil meridional}

Discutiremos neste tópico a construção do trecho catarinense da Estrada de Ferro São Paulo-Rio Grande (EFSPRG) no meiooeste e as mudanças sociais. O objetivo maior era integrar o Rio Grande do Sul a São Paulo. O meio oeste catarinense, cortado pelo Rio do Peixe, pouco povoado, era um território de passagem, mas após a construção da ferrovia (1907-1910) sofreu várias mudanças sociais. 


\section{A construção do trecho catarinense}

Dentro do movimento de ocupação das fronteiras, de transformação de economias naturais em economias mercantis e na busca pela valorização do capital que explorava atividades agrárias voltadas para o mercado externo, o Decreto $\mathrm{n}^{\mathbf{0}} 10.432$ de 09 de novembro de 1889, concedeu a João Teixeira Soares o privilégio para construir uma ferrovia que partisse das margens do Rio Itararé, na província de São Paulo, onde terminava a ferrovia Sorocabana, até Santa Maria, no Rio Grande do Sul, e seus ramais. Com garantia de juros de $6 \%$, durante trinta anos sobre um capital de 37.000:000\$000, Soares ainda tinha o direito de explorar as terras devolutas nas margens da ferrovia por um prazo de cinqüenta anos numa extensão de trinta quilômetros de cada lado. $\mathrm{O}$ contrato foi assinado no dia 14 de novembro de 1889, no apagar das luzes do Império.

Para o governo, a construção de uma ferrovia no oeste catarinense iria ajudar na definição do território, uma vez que desde 1881 a Argentina reivindicava parte significativa do oeste catarinense e paranaense (Questão de Palmas). Após o acordo firmado com a Argentina, em 1895, o governo brasileiro tratou de povoar a região o mais rápido possível. Para tanto, seria necessário criar estruturas viáveis para levar e manter as pessoas na região. Ferrovia, terras, companhias colonizadoras e atividades econômicas rentáveis (erva-mate e madeira) eram as condições necessárias para definir as fronteiras. A função do Estado seria conceder privilégio para a construção de ferrovias e conceder terras devolutas para a colonização. Além da Argentina, o Paraguai significava ainda uma possibilidade de ameaça desde o fim da Guerra do Paraguai (1864-1870).

A extensão do tronco principal e dos ramais somava ao todo $1.952 \mathrm{~km}$, sendo o trecho Itararé-Rio Uruguai o mais importante, dividido em duas seções: Itararé-Porto União e Porto União-Rio Uruguai, com $941 \mathrm{~km}$ (MINISTÉRIO DA INDÚSTRIA VIAÇÃO E OBRAS PÚBLICAS, 1898). Os trabalhos de construção efetivamente foram iniciados no dia 15 de novembro de 1895, a 
partir da cidade de Ponta Grossa no Paraná que seria utilizada com base para atacar as duas linhas: norte, em direção a Itararé, e sul, em direção ao Rio Uruguai (MINISTÉRIO DA INDÚSTRIA, VIAÇÃO E OBRAS PÚBLICAS, 1899). O primeiro trecho foi inaugurado em 16 de dezembro de 1899, numa extensão de 228 $\mathrm{km}$.

Em abril de 1904, a ferrovia chegou às margens do Rio Iguaçu, na divisa com Santa Catarina. Neste momento, estava em operação todo o trecho paranaense, além do gaúcho, entre o Rio Uruguai e Santa Maria, faltando concluir apenas o trecho catarinense entre os rios Iguaçu e Uruguai. Como a Companhia EFSPRG apresentava déficits constantes, as obras do trecho catarinense não começaram no prazo definido.

A situação de insolvência da empresa coincide com a chegada no Brasil do magnata norte-americano Percival Farquhar, que se tornaria proprietário de $57,0 \%$ da malha ferroviária brasileira até a Primeira Guerra Mundial. Em 1906, Farquhar fundou na cidade de Miami, nos Estados Unidos, a Brazil Railway Company (BRC), a holding que ficaria encarregada de controlar suas aquisições ferroviárias brasileiras (LANNA, 2005). Dentre as ferrovias adquiridas estava a EFSPRG e a EFP.

Em 1907, por meio do Decreto $n^{\circ}$ 6.533, o governo deu um ultimato à Companhia EFSPRG para concluir o trecho catarinense de $347 \mathrm{~km}$. O prazo máximo para a conclusão das obras era de três anos, ou seja, deveria ser inaugurada até final de 1910. Também estava previsto no Decreto que o povoamento das terras próximas à ferrovia deveria ser executado por empresas, independente de qualquer iniciativa do governo federal ou estadual. A conclusão da linha Itararé até o Rio Uruguai ligava as ferrovias paulistas às gaúchas, motivo que estimulava a Companhia EFSPRG a apostar no empreendimento, mesmo operando com déficits.

Como o nível do terreno era muito acidentado, as obras no trecho catarinense da EFSPRG foram as mais difíceis de toda a linha tronco. Ela deveria ser construída na margem do Rio do Peixe, desde a sua foz no Rio Uruguai, até a sua nascente, próximo 
à Estação Calmon. As pontes sobre os rios Iguaçu e Uruguai eram as duas maiores obras de arte a serem construídas. No trecho Porto União-Rio Uruguai o número de trabalhadores chegou ao "ponto de exceder 5.000 pessoas" (MINISTÉRIO DA VIAÇÃO E OBRAS PÚBLICAS, 1909, p. 352).

Em 1909, em plena construção do trecho catarinense, a Companhia EFSPRG foi comprada pela BRC, que já havia adquirido a Estrada de Ferro Sorocabana. Farquhar não tardou em adquirir também a EFP e a EFDTC e seus respectivos ramais, formando uma grande rede viária no Paraná e em Santa Catarina. Em 1910, com base no Decreto $\mathrm{n}^{\circ}$ 6.533, as ferrovias catarinenses e as paranaenses, sob a gestão da BRC, formaram a Rede de Viação Férrea Paraná-Santa Catarina.

A compra da Companhia EFSPRG garantia para Farquhar duas grandes fontes de acumulação: a madeira (araucária), pronta para o corte, e as terras disponíveis para colonização. Para explorar a madeira ao longo da ferrovia, nas terras concedidas, em 1909, Farquhar formou nos EUA a Southern Brazil Lumber \& Colonization Company. A Lumber, como era mais conhecida, montou duas grandes serrarias em Santa Catarina, uma na localidade de Calmon, e outra em Três Barras, próxima ao Rio Negro. A serraria de Três Barras era a maior da América Latina e dispunha de equipamentos modernos, empregando na época em torno de 1.800 trabalhadores (THOMÉ, 1983). Para promover a colonização das terras devolutas concedidas à Companhia EFSPRG, foi constituída, em 1912, também nos EUA, a Brazil Development \& Colonization Company. Além de executar diretamente a colonização, a Brazil Development, que recebeu 569.057 hectares de terra, também repassava as concessões para outras companhias (PIAZZA, 1994).

Em outubro de 1910, dentro do prazo fixado pelo governo federal, o trecho Porto União-Rio Uruguai foi entregue para o tráfego (Anexo - Mapa). Com o fim das obras, a linha Itararé-Rio Uruguai alcançou a marca de $883 \mathrm{~km}$. Incluindo todas as linhas, ramais e trechos em estudos, a Rede de Viação Férrea Paraná- 
Santa Catarina, administrada pela BRC, tinha a concessão de 5.148 km (MINISTÉRIO DA VIAÇÃO E OBRAS PÚBLICAS, 1911). A EFSPRG, a Lumber e a Brazil Development, todas de propriedade de Farquhar, formavam uma tríade, que atuava em três frentes de valorização do capital: transporte ferroviário, extração vegetal (madeira e erva-mate) e colonização (venda de terras).

A construção da ferrovia, o extrativismo vegetal e as "frentes pioneiras" no oeste e meio oeste catarinense, se resumem num só elemento que explica a introdução de relações capitalistas de produção na região. Apesar da presença de índios Kaingang e Xokleng, de algumas fazendas de criação e de pequenas roças de caboclos, foi com a construção da estrada de ferro e com a demarcação das terras feita pelas companhias colonizadoras que a região passou a ser ocupada de forma capitalista. Até então, era esparsamente povoada e fracamente monetizada (GOULARTI FILHO, 2002).

Após a Questão de Palmas, o governo catarinense teve de resolver o problema de limites com o estado do Paraná, o chamado Acordo de Limites, em que o governo paranaense reivindicava todo o território oeste catarinense, alegando que essas terras faziam parte de seu território, quando a província tinha sido desmembrada de São Paulo. O problema se arrastou até 1916, quando foi dado ganho de causa para Santa Catarina pelo governo federal. No meio desta disputa, ocorreu a Guerra do Contestado (1912-1916), um conflito entre o exército e os fazendeiros locais contra caboclos despossuídos. Com a colonização e a construção da ferrovia, muitos caboclos foram expulsos de suas terras para darem espaços às novas frentes pioneiras de colonização capitalista. Os caboclos criaram uma irmandade permeada por idéias religiosas e sociais, na busca de terras que haviam perdido. Surgem na região várias figuras lendárias que representavam os ideais dos caboclos e que passaram a desestabilizar os objetivos capitalistas da colonização (AURAS, 1995).

Com o término da Guerra do Contestado, dando vitória aos colonizadores, e com a assinatura do Acordo de Limites, começou 
efetivamente a colonização no oeste e meio oeste catarinense, por colonos gaúchos de origem ítalo e teuto-brasileira, que saíram do noroeste do Rio Grande do Sul basicamente por dois motivos: a falta de novas áreas a serem colonizadas e as transformações da economia fumageira em Santa Cruz, nos anos de 1940. A esses fatos soma-se a promessa do "eldorado", que representava as terras catarinenses. Desenvolveu-se na região uma colonização que era baseada no sistema colônia-venda e na pequena propriedade e que era voltada para a economia de subsistência e para a comercialização do excedente, estimulando desde cedo a formação de um mercado interno, integrando à economia nacional por meio da ferrovia. Havia um universo de pequenas atividades comerciais e manufatureiras como: mercearias, atafonas, marcenarias, moinhos, fábricas de queijo e salame, fábricas de caixas, sapatos e fundição. Esse regime de produção, baseado na pequena propriedade, permitiu uma acumulação lenta e pulverizada, e ao mesmo tempo possibilitou o surgimento de uma diferenciação social em que alguns colonos mais abastados começaram a subordinar o trabalho e a pequena propriedade, tornando-se madeireiros ou proprietários de frigoríficos (GOULARTI FILHO, 2002).

Mesmo com o início das atividades extrativistas e o fim da Guerra do Contestado, a linha Itararé-Rio Uruguai continuou operando com déficits. A madeira era a mercadoria mais transportada, seguida da erva-mate e dos cereais, que eram destinados aos portos de São Francisco do Sul e Paranaguá.

No bojo da Primeira Guerra Mundial, a BRC começou a acumular déficits em quase todas as suas concessões ferroviárias, inviabilizando a manutenção e a expansão das novas linhas. No território catarinense, como a ferrovia margeava o Rio do Peixe, o trecho era muito sinuoso e constantemente sofria com as enchentes, obrigando a reposição de novos dormentes e trilhos. Diante da insolvência da BRC, que vinha se acumulando desde 1915, quando os contratos foram renovados, em julho de 1917 o truste de Farquhar entrou em concordata. Mesmo assim, as ferrovias 
administradas pela antiga holding continuaram em operação, divididas em três regimes: as arrendadas, as concedidas e as de regime especial (COMPANHIA ESTRADA DE FERRO SÃO PAULO-RIO GRANDE, 1928). A Lumber e a Brazil Development ainda continuaram em atividade, controladas por Farquhar.

Com o advento da Revolução de 1930, as ferrovias brasileiras de interesse nacional foram tomadas pelas forças revolucionárias, que as mantiveram ocupadas até ser definida sua nova concessão. O Decreto $\mathrm{n}^{\mathrm{o}} 19.601$ de 1931 regulamentou a ocupação da Rede de Viação Paraná-Santa Catarina (RVPRSC) e prorrogou a data da ocupação. Nos anos seguintes, foram editados sucessivos decretos que prorrogaram a data de ocupação até que fosse resolvido em definitivo o destino da RVPRSC, que passou a atuar como superintendência vinculada ao Ministério da Viação e Obras Públicas.

Nos anos de 1930, as ferrovias no Sul, excluindo a Estrada de Ferro Dona Tereza Cristina, que havia sido arrendada para uma companhia carbonífera, estavam todas sendo controladas pelo Estado. No Rio Grande do Sul, a estatal Viação Férrea do Rio Grande do Sul (VFRGS) administrava a malha gaúcha desde 1920; em Santa Catarina, a pequena Estrada de Ferro Santa Catarina (ESFC), no Vale do Itajaí, estava arrendada para o governo estadual, e a linha São Francisco do Sul e o trecho Porto União-Rio Uruguai estavam sob o comando federal; e no Paraná, todas as ferrovias eram federais. Neste período, os investimentos federais da RVPRSC concentraram-se apenas no Paraná e na integração com as ferrovias paulistas. Após a conclusão da linha São Francisco do Sul em 1917, não houve mais investimentos da RVPRSC, em território catarinense, para ampliar a rede, apenas para manter a malha existente.

Dentro do projeto nacional de industrialização no bojo da centralização das tomadas de decisão na mão do Estado, em 1940 o Decreto $\mathrm{n}^{\circ} 2.073$ incorporou ao patrimônio da União a EFSPRG, que na oportunidade controlava também a EFP. E para resolver problemas de ordem jurídica e financeira, finalmente em 1942, o 
Decreto $n^{0} 4.746$ instituiu com personalidade própria de natureza autárquica a Rede de Viação Paraná-Santa Catarina, subordinada ao Ministério da Viação e Obras Públicas. Para Santa Catarina, pouco alterou esta mudança, uma vez que o escritório central ficou em Curitiba e a malha ferroviária catarinense não foi ampliada. A promessa era construir o Tronco Principal Sul (TPS), ligando Curitiba a Porto Alegre, passando por Mafra e Lages, como linha alternativa a Itararé-Santa Maria. Neste momento, o Brasil estava entrando na era rodoviária, em que os ônibus e os caminhões ocupavam o lugar dos trens e as estradas pavimentadas, o lugar dos trilhos.

\section{Ferrovia e mudanças no meio-oeste catarinense}

No início do século XX, a reserva brasileira de pinheiro era de aproximadamente $200.000 \mathrm{~km}^{2}$ de superfície, e, em 1955, Santa Catarina representava $12,2 \%$ da área total de floresta araucária (LAGO, 1968). O pinheiro (mata araucária), a imbúia e a canela (mata atlântica) eram as árvores mais exploradas. Além da disponibilidade de recursos naturais, o surgimento de outras atividades ligadas à exploração da madeira tem a ver com a expansão da produção artesanal, que estava vinculada ao alargamento do mercado interno.

A indústria madeireira, por um lado, teve início com a instalação da Lumber, e por outro, as primeiras pequenas serrarias, de propriedade dos colonos imigrantes, que inicialmente se instalaram como comerciantes, transformaram-se mais tarde em industriais. Entre as colônias fundadas por imigrantes em Santa Catarina, as localizadas no meio oeste e planalto norte foram as que mais se dedicaram às atividades madeireiras. A extração da madeira e a colonização fixavam os colonos na terra (GRIGGS, 1974).

Uma parte da produção da madeira do oeste era destinada ao mercado argentino e uruguaio, transportada por meio do Rio Uruguai, em forma de balsa, durante o período de cheias. A outra 
parte era transportada pela EFSPRG até a cidade de Porto União, que seguia até o porto de São Francisco do Sul (BELLANI, 1991).

Segundo Campos (1987), excluindo algumas produções vinculadas às empresas colonizadoras gaúchas, a maioria dos estabelecimentos comerciais e industriais foi formado com capitais acumulados localmente. Do ponto de vista comercial, a madeireira foi o elemento integrador da região no mercado nacional. No planalto norte e Alto Vale do Rio do Peixe, tendo Canoinhas e Caçador, respectivamente, como municípios pólos, a madeira ainda é a principal atividade industrial na região. $\mathrm{Na}$ região oeste, a atividade madeireira basicamente esgotou-se no início dos anos de 1950. Ao contrário do planalto norte e serrano, a região oeste não partiu para o reflorestamento.

Além de a madeira ser transportada pelos trilhos da EFSPRG, o mesmo acontecia com a produção agrícola e pecuária; esta última pautada em suínos e aves. Nos anos de 1940 sugiram os primeiros frigoríficos na região oeste, que rapidamente se integraram ao mercado nacional. A diversificação para o setor alimentício manteve a expansão da renda e formou na região oeste e meio oeste importantes segmentos do complexo agroindustrial de carne, pautado em grandes frigoríficos e pequenos agricultores (GOULARTI FILHO, 2002).

A partir dos anos de 1960, quando o complexo agroindustrial de carne começou a se consolidar no oeste e meio oeste catarinense, o Brasil já estava na era rodoviária. Para escoar a produção dos frigoríficos aos centros consumidores e aos portos, foram utilizadas mais as rodovias do que as ferrovias. A pavimentação da BR-153, BR-116, BR-280 e BR-470 permitiu acelerar a distribuição da produção agropecuária de toda a região. A ferrovia continuava transportando madeira, cereais, manufaturados e bebidas, mas o volume de carga caía continuamente. $\mathrm{O}$ transporte de passageiros, como em boa parte das ferrovias brasileiras, começou a ser desativado a partir da segunda metade dos anos 1960. 
Com a criação da Rede Ferroviária Federal Sociedade Anônima (RFFSA) em março de 1957, por meio do Decreto $\mathrm{n}^{\mathrm{o}}$ 3.115, foram incorporadas as estradas de ferro de propriedade da União e as por ela administradas, bem como aquelas cujos contratos de arrendamento foram rescindidos. Neste pacote de incorporação, estava a RVPRSC, que, em setembro do mesmo ano, passou a ser diretamente subordinada à RFFSA.

Dentro da reorganização administrativa da RFFSA, em 1969, a RVPRSC foi extinta e transformada em $11^{\mathrm{a}}$ Divisão Paraná-Santa Catarina e, em 1976, passou a ser designada SR-5 Superintendência Regional de Curitiba. Sob a operação da RFFSA, houve uma expansão da malha ferroviária catarinense com a construção do trecho no planalto catarinense, Mafra a Lages, inaugurado em 1968. Este novo trecho passou a ser controlado pela SR-5.

Com a concessão à iniciativa privada da Malha Sul (SC, PR e RG) em 1997, entrou em operação a Ferrovia Sul Atlântico SA (FSA), que desativou alguns trechos poucos utilizados e deficitários. Entre ele estava Porto União-Rio Uruguai. Com a entrada em operação do trecho no planalto catarinense em 1968, a antiga linha EFSPRG passou a ser menos utilizada. A diferença entre os dois trechos residia na velocidade permitida na linha, uma vez que a antiga EFSPRG margeava o Rio do Peixe, que é muito sinuoso, e o trecho no planalto segue longos percursos em linha reta.

Durante os últimos anos de gestão estatal, a antiga EFSPRG em Santa Catarina era mais utilizada como uma linha alternativa, quando ocorriam problemas no trecho Mafra-Lages. Não interessava à RFFSA abandoná-la, mas sim manter as vias permanentes em bom estado de conservação, mesmo sendo deficitárias. O mesmo não ocorre com a América Latina Logística (ALL), antiga FSA, que simplesmente abandonou o trecho Passo Fundo a Porto União.

Atualmente, são utilizados pequenos trechos que exploram o turismo ferroviário, como o entre Piratuba (SC) e Marcelino 
Ramos (RS) e em Porto União (até a estação Eugênio de Melo). No momento, a ALL se compromete em fazer pequenos reparos na linha, mas, de acordo com o contrato de concessão, a empresa obrigatoriamente deverá reutilizar a ferrovia, mesmo sendo deficitária.

\section{Ramal Porto União-São Francisco}

Neste tópico abordaremos a construção da Linha São Francisco (Ramal Porto União-São Francisco do Sul), que segue até Porto União, construída entre 1906 e 1917, e a integração com o antigo Tronco Sul da RFFSA, que segue para Lages, construída entre 1961 a 1968.

\section{A linha São Francisco}

A tentativa de ligar o litoral sul-brasileiro até a fronteira do Paraguai remonta ao Tratado de Aliança Defensiva assinado em Assunção, no dia 25 de dezembro de 1850, quando ficou acordado no Artigo XIII que seria prevista a abertura de estradas rápidas e seguras para estabelecer comunicações regulares entre as duas nações (REPARTIÇÃO DOS NEGÓCIOS ESTRANGEIROS, 1852). Com os adventos da Guerra do Paraguai (1864-1870), os propósitos assinados no Tratado foram abandonados e a integração com o Paraguai não era mais prioridade para o governo brasileiro. Com o fim do conflito, a Argentina passou a reivindicar o território de Palmas, questão que ficou resolvida somente em 1895.

No Decreto de 1889, que concedeu a João Teixeira Soares o privilégio para a construção da linha Itararé-Santa Maria, também estava previsto a construção de dois ramais que seguissem em direção à fronteira do Paraguai.

No ano seguinte, o coronel engenheiro Dionício Cerqueira e Carlos Napoleão, o engenheiro civil Ricardo Longe, o capitão engenheiro João do Rego Barros e o capitalista João Marcílio Pereira Moraes apresentaram uma proposta ao Ministério da Agricultura para abrir uma estrada de ferro, partindo do porto de 
São Francisco do Sul, seguindo até o povoado de Tucurupucú, no Paraguai (MINISTÉRIO DA AGRICULTURA, COMÉRCIO E OBRAS PÚBLICAS, 1890). O Decreto 896/1890 concedeu o privilégio e a garantia de juros para ser construída essa estrada de ferro, com algumas mudanças em relação à proposta apresentada ao Ministério.

$\mathrm{Na}$ Exposição Financeira e Técnica apresentada pela Companhia EFSPRG em 1900, foi reforçada a intenção de construir um ramal entre o Rio Iratí ao porto de São Francisco do Sul, que foi garantido no ano seguinte com a publicação do Decreto $\mathrm{n}^{\circ}$ 3.947, que fez uma ampla revisão das concessões feitas à Companhia (COMPANHIA ESTRADA DE FERRO SÃO PAULO-RIO GRANDE, 1900). Com a conclusão do primeiro trecho da EFSPRG até as margens do Rio Iguaçu, em 1904, foi baixado o Decreto $\mathrm{n}^{\mathrm{o}} 5.280$ de 1904 que aprovou os estudos definitivos e o respectivo orçamento do primeiro trecho da linha ferroviária, ligando o porto de São Francisco do Sul até a vila de São Bento, passando pela cidade de Joinville e Jaraguá, numa extensão de $144 \mathrm{~km}$. Logo em seguida os trabalhos foram iniciados, partindo da cidade de São Francisco do Sul (MINISTÉRIO DA VIAÇÃO E OBRAS PÚBLICAS, 1905).

Durante a execução da obra, o projeto foi redefinido, sendo concluído apenas $96 \mathrm{~km}$ de vias permanentes, ligando São Francisco do Sul a Hansa (atual Corupá), passando por Joinville e Jaraguá. No dia 29 de julho de 1906, foi inaugurado em Joinville o primeiro trecho desta linha. Esta ferrovia estava dentro das vias de comunicação que formava o complexo ervateiro do Paraná e Santa Catarina.

A expansão acelerada da extração da erva-mate no Paraná começou a partir do último quartel do século XIX. Esta vegetação faz parte da mata araucária, que cobria quase todo o território do Paraná e Santa Catarina (planalto norte, planalto serrano e parte do meio oeste). A produção era destinada ao mercado externo, Argentina e Uruguai e também para o mercado interno, Rio Grande do Sul. Para escoar a produção, foi criado um sistema de transporte 
que combinava ferrovias, navegação fluvial, estradas de rodagem e portos. As primeiras vias de comunicação construídas para ligar o segundo planalto paranaense, onde estava concentrada a extração da erva-mate, com os portos de Antonina e Paranaguá, no primeiro planalto, foram a Estrada da Graciosa, a do Itapuava e a do Arraial. Como o percurso era muito lento e a produção de erva-mate crescia constantemente, em 1880 foi iniciada a construção do trecho ferroviário entre Paranaguá e Curitiba, da EFP. Após a inauguração em 1885, foi iniciada a construção de ramais que ligavam as áreas produtoras de erva-mate com a EFP. Pela via fluvial, a erva-mate descia o Rio Iguaçu, desde a cidade de Porto Amazonas a Porto União, que seguia pelo Rio Negro até a cidade de Mafra, de onde partiam os comboios de carroções (sãobentowagen) descendo a Estrada Dona Francisca à cidade de Joinville. Em Joinville era feito o beneficiamento da erva que seguia por via fluvial (Rio Cachoeira) até o porto de São Francisco do Sul (MARTINS, 1932; FICKER, 1965).

A construção da Linha São Francisco substituiria a Estrada Dona Francisca, e os trens, os carroções. Portanto, temos que entender a construção da linha entre Porto União até o porto de São Francisco do Sul, como expansão das vias de comunicação do complexo ervateiro, tal como foi a expansão das ferrovias paulistas no complexo cafeeiro.

O Decreto $n^{\circ} 6.533$ de 1907, que fixou o prazo para a conclusão do trecho catarinense da EFSPRG, também determinou que deveriam ser concluídos os estudos definitivos da linha do porto de São Francisco do Sul ao Rio Paraná, que se estenderia até as linhas ferroviárias do Paraguai. O Contrato do Decreto 7.928/1910, que autorizou a revisão do contrato com a EFSPRG, previa o seguinte:

A Companhia Estrada de Ferro S. Paulo-Rio Grande obriga-se a celebrar os acordos necessários para fazer a ligação da linha de S. Francisco à foz do Rio Iguaçu com as linhas do Paraguai no ponto que for julgado mais conveniente, construindo para isso o ramal e estabelecendo 
a ligação fluvial. De 18 meses, para a conclusão dos estudos da linha de São Francisco até a foz do Iguaçu; De três anos, para ficar concluída a construção da mesma linha até o porto da União da Vitória, e de cinco anos, para a sua conclusão até a foz do Iguaçu, devendo a construção ser atacada, desde logo, em diversos pontos aos quais houver acordo por via-férrea (DECRETO No 7.928 de1910).

Neste mesmo ano, a BRC incorporou a estrada de ferro no Paraguai que possibilitaria a integração com a EFSPRG, por meio de uma extensa linha entre São Francisco-Assunção.

Obtido o assentimento do governo do Paraguai, a Companhia Estrada de Ferro S. Paulo-Rio Grande obriga-se a ligar à sua rede a estrada de ferro que, segundo concessão do mesmo governo do Paraguai, se dirija de Assunção, capital dessa República, à foz do Iguaçu ou a outro lugar mais conveniente nas proximidades do salto das Sete Quedas, ponto terminal da estrada que parte do porto de S. Francisco, no Estado brasileiro de Santa Catarina, constituindo as duas estradas uma linha contínua que se chamará, com a aprovação dos governos dos dois países interessados, Estrada de Ferro Brasil-Paraguai (DECRETO No 8.270 de 1910).

Esta estrada nunca foi construída. Em 1911, após a inauguração do trecho Rio Iguaçu-Rio Uruguai, foram iniciados os trabalhos de conclusão da Linha São Francisco, partindo de Corupá e Porto União (MINISTÉRIO DA VIAÇÃO E OBRAS PÚBLICAS, 1912). O trecho entre Corupá e Três Barras, passando por Mafra, com $219 \mathrm{~km}$, foi aberto para o tráfego no dia $1^{\circ}$ de abril de 1913, e o trecho entre Três Barras e Canoinhas, com $11 \mathrm{~km}$, foi entregue no dia $1^{\circ}$ de outubro do mesmo ano (MINISTÉRIO DA VIAÇÃO E OBRAS PÚBLICAS, 1915). Os prazos para entrega do trecho entre Canoinhas e Porto União foram prorrogados, uma vez o que Decreto ${ }^{\circ} 6.533$ de 1907 definia que as obras deveriam ser entregues em 1910. A linha começou operando com déficit, mas a esperança era de que com a sua extensão em tráfego a situação seria revertida (SANTA CATARINA, 1911). 
A origem da indústria do norte catarinense tem suas raízes no desdobramento da acumulação capitalista do complexo ervateiro, que combinou com a presença da pequena produção mercantil. Além de a erva-mate fomentar o início das pequenas atividades indústrias, ela contribuiu para fixar os colonos na região. Em torno do beneficiamento da erva surgiram pequenas oficinas de reparos dos carroções que a transportavam e pequenas serrarias e marcenarias que confeccionavam as barricas onde era armazenada. Também surgiram atividades ligadas à construção e manutenção da Estrada Dona Francisca e, em seguida, do ramal ferroviário. Segundo Almeida (1979), podemos afirmar que a origem da indústria joinvillense é uma conseqüência da formação e da expansão do complexo ervateiro.

O pequeno comércio local, em Joinville e São Bento do Sul, foi estimulado pela expansão da renda, promovida pelas atividades ervateiras. Vários pequenos produtores e comerciantes, segundo Rocha (1997), que nada tinham a ver com o complexo ervateiro, também entraram no ramo, beneficiando - por meio de engenhos ou comercializando - por meio de firmas exportadoras - a ervamate. Ferrovia, erva-mate e pequena produção mercantil se combinaram e formaram a fonte originária da acumulação do norte catarinense, que desdobrou um parque industrial metal-mecânico, vestuário e mobiliário.

Com relação às demais ferrovias em Santa Catarina, no Relatório de 1915 da Secretaria de Negócios do Estado, apresentado ao governador, o secretário Fulvio Aducci argumentava que, das quatro ferrovias existentes em Santa Catarina, apenas a Linha São Francisco era a mais importante. A EFSC era tão-somente uma ferrovia municipal, a EFDTC ficou reduzida a uma linha secundária e quase inútil, a EFSPRG cortava uma região que estava sob jurisdição do Paraná, já a Linha São Francisco:

É a mais importante e a que melhor corresponde às necessidades da nossa produção e exportação. Partindo do porto de São Francisco [...] e estendendo seus trilhos 
por uma zona riquíssima de erva e madeira e que se prestam para a cultura de quaisquer cereais e para a criação em larga escala, essa linha será dentro em pouco tempo um dos maiores elementos do nosso progresso (SECRETARIA GERAL DOS NEGÓCIOS DO ESTADO, 1915, p. 190).

No futuro, segundo o Relatório da Secretaria, a linha estaria integrada com Mato Grosso, Paraguai e Bolívia, tornando-se num "grande caminho" por onde passariam as mercadorias destinadas ao mercado norte-americano e europeu.

A Linha São Francisco também foi incorporada quando foi criada, pela BRC, a Rede de Viação Paraná-Santa Catarina em 1910. Mesmo numa situação de insolvência, a BRC seguia com a construção de alguns ramais previstos nos contratos, sendo que outros nunca foram executados. Como a Linha São Francisco estava quase pronta, não compensava mais parar. Ligar a EFSPRG com o porto de São Francisco do Sul para escoar a madeira da Lumber e a erva-mate, talvez fosse uma saída para os constantes déficits gerados pela ferrovia.

\section{Integrando com o planalto norte catarinense}

No dia 20 de agosto de 1917, foi inaugurado o tráfego provisório entre Canoinhas e Porto União, elevando para $463 \mathrm{~km}$ a extensão total da linha (Anexo - Mapa). Neste mesmo ano, a BRC entra em concordata, e o projeto para chegar até a fronteira com o Paraguai foi abandonado. Houve uma tentativa do governo catarinense de retomá-lo em 1921, mas seria algo insustentável para o tesouro estadual (KONDER, 1921).

Como a Linha São Francisco fazia parte da Companhia EFSPRG, em 1930 ela também foi encampada pelo governo federal. As mudanças jurídicas que ocorreram com a RVPRSC nas décadas seguintes também repercutiram na Linha São Francisco. De 1930 a 1960, esta linha serviu como grande corredor de transporte de madeira e cereais do meio oeste e planalto norte catarinense. Como havia dois entroncamentos, um em Porto União, 
que ligava com Irati, seguindo para o norte do Paraná, e outro em Mafra, que ligava com a EFP, parte expressiva das cargas que desciam pela Linha São Francisco era proveniente do Paraná. Há de se ressaltar que, quando o projeto desta linha foi apresentado pela EFSPRG, grande parte do território por onde passaria a ferrovia era pretendido pelo governo do Paraná.

Com a entrada em operação do Tronco Sul da RFFSA, que ligava Lages a Mafra em 1968, o tráfego da ferrovia do meio oeste catarinense, que era muito lento, foi sensivelmente reduzido (Anexo - Mapa). Com isso, o trecho entre Porto União e Mafra também sofreu queda no movimento. Nos anos de 1980 foi desativado o trecho entre Porto União e Irati, que levou a deterioração ainda maior do trecho até Mafra.

A expansão da safra agrícola paranaense e o aumento exponencial da produção de soja mudaram o perfil das ferrovias do Paraná, com relação às cargas transportadas. Além dos grãos, começaram a ser transportados derivados de petróleo e cimento. Dentro do programa dos corredores de exportações do governo federal, posto em prática a partir do início dos anos de 1970, o porto de Paranaguá foi selecionado como plataforma de embarque da soja proveniente do Paraná e parte do Centro-Oeste brasileiro. Paralelo às ferrovias paranaenses, o sistema rodoviário transformou-se na via arterial para escoar a safra agrícola brasileira.

A pavimentação da BR-280, que corta todo norte catarinense, fez reduzir ainda mais o tráfego na Linha São Francisco. Com a concessão da Malha Sul para América Latina Logística 1997, o trecho entre Mafra e o porto de São Francisco do Sul voltou a operar com mais intensidade. O turismo também se faz presente neste trecho entre as estações de Rio Negrinho e Rio Natal, próximo a Corupá.

Atualmente, trafegam no trecho Mafra-São Francisco do Sul parte da safra agrícola do Centro-Oeste e do Paraná. O porto de São Francisco do Sul tornou-se uma opção em relação à Paranaguá, que nos períodos de safra opera próximo da capacidade 
instalada. Além dos grãos, também são transportados granel líquido, principalmente de óleo de soja. Ambos os portos estão preparados para receber e armazenar estes dois tipos de cargas.

Portando, a Linha São Francisco foi se adaptando às especializações regionais. Construída para escoar erva-mate e madeira, passou por uma crise e se recuperou com o transporte da safra agrícola, principalmente da soja. Hoje a antiga Linha São Francisco, que passou a se chamar Ramal Porto União-São Francisco do Sul faz parte do complexo agroindustrial de soja.

\section{Conclusão}

Com base no Decreto $\mathrm{n}^{\mathrm{o}} 8.987$ de 1995, e no Programa Nacional de Desestatização, a Ferrovia Sul Atlântico SA, atual América Latina Logística do Brasil SA (ALL), ganhou a concessão da Malha Sul da RFFSA no leilão ocorrido no dia 13 de dezembro de 1996. A empresa entrou em operação no dia $1^{\circ}$ de março de 1997. Atualmente, a ALL administra uma malha ferroviária de $20.495 \mathrm{~km}$, participando com $30,0 \%$ do mercado ferroviário brasileiro e $36,0 \%$ do argentino. A frota é composta por dois mil veículos, 960 locomotivas e 27 mil vagões. Todo o antigo Tronco Sul, que cobria os três estados do Sul e parte de São Paulo, foi concedido à ALL.

Santa Catarina nunca teve um sistema ferroviário que servisse de elemento integrador do mercado regional. A economia catarinense foi se formando, integrando-se primeiramente com o mercado nacional. As ferrovias atuavam de forma isoladas, seja no sul, transportando carvão, no Vale do Itajaí, atendendo às colônias, ou no meio oeste e norte, transportando madeira e erva-mate.

Talvez a pergunta que mais vem à tona é por que nunca houve uma malha ferroviária catarinense capaz de integrar o mercado regional? Se fôssemos pensar apenas do ponto de vista econômico, a resposta seria simples: não haveria fluxo suficiente de mercadorias que justificasse a implantação de um sistema ferroviário integrado, ou seja, a acumulação regional seria muito lenta e dispersa. 
Uma ferrovia não se implanta com intenção de desenvolver uma região onde não há uma atividade econômica importante. Mas, pelo contrário, uma ferrovia é construída para atender a uma região onde há uma grande atividade econômica que a sustente financeiramente, acelerando a circulação para aumentar a produção.

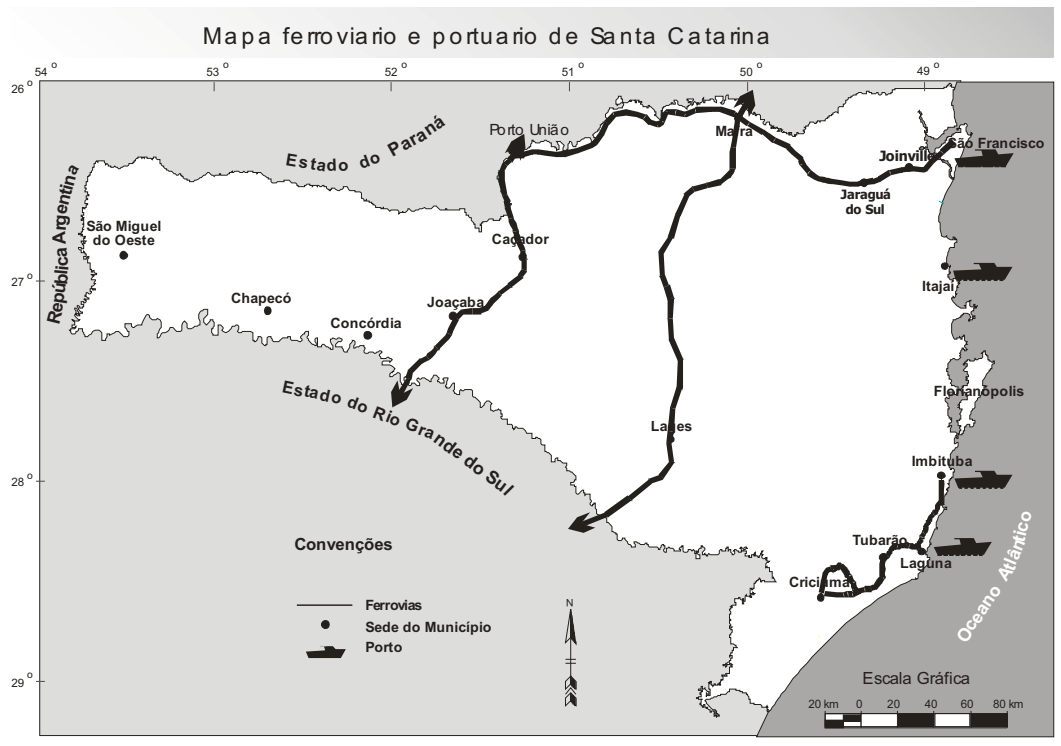

\section{Referências bibliográficas}

\section{Relatórios}

COMPANHIA ESTRADA DE FERRO SÃO PAULO-RIO GRANDE. Exposição financeira e técnica. Rio de Janeiro: Tipografia Leuzinger, 1895.

Exposição financeira e técnica. Rio de Janeiro: Tipografia do Jornal do Comércio, 1900.

Memorial formulado pelo engenheiro civil $\mathbf{J}$. Moreira Garcez. Curitiba: Empresa Gráfica Paranaense, 1928. 
MINISTÉRIO DA AGRICULTURA, COMÉRCIO E OBRAS PÚBLICAS. Requerimento - Documento avulso. Rio de Janeiro, 20 de junho, 1890.

MINISTÉRIO DA INDÚSTRIA, VIAÇÃO E OBRAS PÚBLICAS. Relatório apresentado pelo Ministro Severino dos Santos Vieira ao Presidente da República no ano de 1898. Rio de Janeiro: Imprensa Nacional, 1898.

Relatório apresentado pelo Ministro Severino dos Santos ao Presidente da República no ano de 1899. Rio de Janeiro: Imprensa Nacional, 1899.

. Relatório apresentado pelo Ministro Lauro Severino Müller ao Presidente da República no ano de 1903. Rio de Janeiro: Imprensa Nacional, 1903.

Relatório apresentado pelo Ministro Lauro Severino Müller ao Presidente da República no ano de 1904. Rio de Janeiro: Imprensa Nacional, 1905.

. Relatório apresentado pelo Ministro Miguel Calmon du Pin e Almeida ao Presidente da República no ano de 1909. Rio de Janeiro: Imprensa Nacional, 1909.

- Relatório apresentado pelo Ministro Augusto

Tavares de Lyra ao Presidente da República no ano de 1914. Rio de Janeiro: Imprensa Nacional, 1915.

REDE FERROVIÁRIA FEDERAL AS. Ferrovia ParanaguáCuritiba 1885 - 2 de fevereiro - 1985: uma viagem de 100 anos. Curitiba: Superintendência Regional de Curitiba, 1985.

- Anuário estatístico da RFFSA. Rio de Janeiro: Departamento de Estatística e Documentação, 1964-1986.

REDE DE VIAÇÃO PARANÁ-SANTA CATARINA. Relatórios apresentados ao Ministério da Viação e Obras Públicas (vários anos). Curitiba: MVOP, 1935-1956. 


\section{Relatórios dos Departamentos e Serviços} apresentados a Rede Ferroviária Federal SA. Curitiba: RFFSA, 1962-1963.

RFFSA, 1966.

A conjugação rodoferroviária na RVPRSC. Curitiba: ferroviária. Curitiba: RFFSA, 1965.

REPARTIÇÃO DOS NEGÓCIOS ESTRANGEIROS. Relatório apresentado pelo Ministro Paulino José Soares de Souza à Assembléia Geral Legislativa. Rio de Janeiro: Universal de Laemment, 1852.

SANTA CATARINA. Mensagem apresentada ao Congresso Representativo pelo governador Vidal José de Oliveira Ramos em julho de 1911. Florianópolis: Tipografia do Dia, 1911.

Mensagem apresentada ao Congresso

Representativo pelo governador Vidal José de Oliveira Ramos em junho de 1914. Florianópolis: Tipografia do Dia, 1914.

SECRETARIA GERAL DOS NEGÓCIOS DO ESTADO. Relatório apresentado pelo Secretário Honório H. Carneiro da Cunha em junho de 1910. Florianópolis, 1910.

Secretário Fulvio Aducci em junho de 1915. Florianópolis: Tipografia do Dia, 1915.

- Relatório apresentado ao Governador pelo Secretário Fulvio Aducci no ano de 1916. Florianópolis: Tipografia do Dia, 1917.

Decretos e Leis

BRASIL. Decreto no 10.432 de 09 de novembro de 1889.

Brasília: Senado Federal. Disponível em:

$<$ http://www.senado.gov.br/servelet $>$ Acesso em: 20 nov. 2006. 
GOULARTI FILHO, A. A Estrada de Ferro São Paulo-Rio Grande na ...

Decreto $n^{\circ} 159$ de 15 de janeiro de 1890. Brasília:

Senado Federal. Disponível em:

$<$ http://www.senado.gov.br/servelet> Acesso em: 20 nov. 2006.

Decreto $n^{0} 305$ de 07 de abril de 1890. Brasília:

Senado Federal. Disponível em:

$<$ http://www.senado.gov.br/servelet> Acesso em: 20 nov. 2006.

Decreto n 896 de 18 de outubro de 1890. Brasília:

Senado Federal. Disponível em:

$<$ http://www.senado.gov.br/servelet $>$ Acesso em: 20 nov. 2006.

Decreto $\mathrm{n}^{\circ} 1.386$ de 06 de maio de 1893. Brasília:

Senado Federal. Disponível em:

$<$ http://www.senado.gov.br/servelet> Acesso em: 20 nov. 2006.

Decreto no 3.947 de 07 de março de 1901. Brasília:

Senado Federal. Disponível em:

$<$ http://www.senado.gov.br/servelet> Acesso em: 20 nov. 2006.

Decreto $n^{0} 5.280$ de 09 de agosto de 1904. Brasília:

Senado Federal. Disponível em:

$<$ http://www.senado.gov.br/servelet> Acesso em: 20 nov. 2006.

Decreto $n^{0} 6.533$ de 20 de junho de 1907. Brasília:

Senado Federal. Disponível em:

$<$ http://www.senado.gov.br/servelet $>$ Acesso em: 20 nov. 2006.

Decreto $n^{0} 7.928$ de 31 de março de 1910. Brasília:

Senado Federal. Disponível em:

$<$ http://www.senado.gov.br/servelet> Acesso em: 20 nov. 2006.

Decreto no 13.801 de 09 de outubro de 1919.

Brasília: Senado Federal. Disponível em:

$<$ http://www.senado.gov.br/servelet $>$ Acesso em: 20 nov. 2006.

Decreto no 19.601 de 19 de janeiro de 1931. Brasília:

Senado Federal. Disponível em:

$<$ http://www.senado.gov.br/servelet> Acesso em: 20 nov. 2006. 
GOULARTI FILHO, A. A Estrada de Ferro São Paulo-Rio Grande na ...

Decreto $n^{0} 24.497$ de 29 de junho de 1934. Brasília:

Senado Federal. Disponível em:

$<$ http://www.senado.gov.br/servelet> Acesso em: 20 nov. 2006.

Decreto $n^{0} 2.073$ de 08 de março de 1940. Brasília:

Senado Federal. Disponível em:

$<$ http://www.senado.gov.br/servelet> Acesso em: 20 nov. 2006.

\section{Decreto $n^{0} 4.746$ de 25 de setembro de 1942.}

Brasília: Senado Federal. Disponível em:

$<$ http://www.senado.gov.br/servelet $>$ Acesso em: 20 nov. 2006.

Decreto no 36.266 de 30 de setembro de 1954.

Brasília: Senado Federal. Disponível em:

$<$ http://www.senado.gov.br/servelet> Acesso em: 20 nov. 2006.

Decreto $n^{0} 36.072$ de 27 de novembro de 1954.

Brasília: Senado Federal. Disponível em:

$<$ http://www.senado.gov.br/servelet $>$ Acesso em: 20 nov. 2006.

Decreto no 3.115 de 16 de março de 1957. Brasília:

Senado Federal. Disponível em:

$<$ http://www.senado.gov.br/servelet> Acesso em: 20 nov. 2006.

Decreto $n^{0} 50.590$ de 15 de maio de 1961. Brasília:

Senado Federal. Disponível em:

$<$ http://www.senado.gov.br/servelet $>$ Acesso em: 20 nov. 2006.

Decreto $n^{0} 56.050$ de 26 de abril de 1965. Brasília:

Senado Federal. Disponível em:

$<$ http://www.senado.gov.br/servelet> Acesso em: 20 nov. 2006.

Decreto $n^{0} 8.987$ de 13 de fevereiro de 1995.

Brasília: Senado Federal. Disponível em:

$<$ http://www.senado.gov.br/servelet> Acesso em: 20 nov. 2006.

. Lei $n^{0} 2.975$ de 27 de novembro de 1956. Brasília:

Senado Federal. Disponível em:

$<$ http://www.senado.gov.br/servelet> Acesso em: 20 nov. 2006.

Livros, dissertações e artigos 
ALMEIDA, Rufino Porfírio. Um aspecto da economia de Santa Catarina: a indústria ervateira - o estudo da Companhia Industrial. Florianópolis: UFSC/CCH, 1979. (Dissertação de mestrado).

AURAS, Marli. Guerra do Contestado: a organização da irmandade cabocla. Florianópolis: Editora da UFSC, 1995.

BELLANI, Eli Maria. Madeira, balsas e balseiros no Rio Uruguai: o processo de colonização do velho município de Chapecó (1917-1950). Florianópolis: UFSC/CFH, 1991. (Dissertação de mestrado)

CAMPOS, Índio. Os colonos do Rio Uruguai: relações entre pequena produção e agroindústrias no oeste catarinense. Campina Grande: UFPB, 1987. (Dissertação de mestrado)

CONSELHO NACIONAL DE TRANSPORTES. Planos de viação: evolução histórica (1808-1973). Brasília: Ministério dos Transportes, 1973.

LANNA, Ana Lúcia Duarte. Ferrovias no Brasil 1870-1920. História Econômica e História de Empresas. São Paulo: ABPHE; Hucitec, v. 8, n. 1, jan-jun, 2005.

FICKER, Carlos. História de Joinville: subsídio para a crônica da colônia Dona Francisca. Joinville: Ypiranga, 1965.

GOULARTI FILHO, Alcides. Formação econômica de Santa Catarina. Florianópolis: Cidade Futura, 2002.

GRIGGS, Rosemari Pozzi Eduardo. A madeira em Santa Catarina 1930-1970. Curitiba: UFPR, 1974. (Dissertação de mestrado)

KONDER, Adolpho. A ligação ferroviária do Paraguai ao Atlântico: defesa do traçado São Francisco-Assunção. Rio de Janeiro: Revista dos Tribunais, 1921.

KROETZ, Lando Rogério. As estradas de ferro de Santa Catarina 1910-1960. Curitiba: UFPR, 1975. (Dissertação de mestrado) 
. As estradas de ferro do Paraná 1880-1940. São

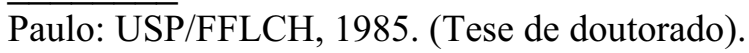

LAGO, Paulo Fernando. Santa Catarina: a terra, o homem e a economia. Florianópolis: Ed. da UFSC, 1968.

MARTINS, Alfredo Romário. O Rio Iguaçu e sua função civilizadora. In: MANSUR, Aziz. Álbum comemorativo do cinqüentenário da navegação no Iguaçu e seus afluentes. Curitiba, 1932.

Caminhos históricos do Paraná. In: REDE DE VIAÇÃO PARANÁ-SANTA CATARINA. Cinqüentenário da Estrada de Ferro do Paraná 1885-1935. Curitiba, 1935.

ROCHA, Isa de Oliveira. Industrialização de Joinville-SC: da gênese às exportações. Florianópolis: Ed. do Autor, 1997.

PIAZZA, Walter F. A colonização de Santa Catarina. Florianópolis: Lunardelli, 1994.

THOMÉ, Nilson. Trem de ferro: a ferrovia no contestado. Florianópolis: Lunardelli, 1983. 
